\title{
Fermentation profile and optimization of green olive fermentation using Lactobacillus plantarum LPCO10 as a starter culture
}

Ma VEGA LEAL-SÁNCHEZ, J.L. RUIZ-BARBA, A.H. SÁNCHEZ, L. REJANO, R. JIMÉNEZ-DÍAZ and A. GARRIDO*

Departamento de Biotecnología de Alimentos, Instituto de la Grasa (Consejo Superior de Investigaciones Científicas), 41012 Sevilla, Spain

Running title: Fermentation profile and optimization...

*Corresponding author. Mailing address:

Departamento de Biotecnología de Alimentos

Instituto de la Grasa (CSIC)

Avda. Padre García Tejero, 4

Aptdo. 1078

41012 Sevilla, Spain.

Phone: (34) 954 602516/1054. Fax: (34) 954 691262. E-mail address: garfer@cica.es 


\section{Summary}

The bacteriocin producer Lactobacillus plantarum LPCO10, a strain originally isolated from an olive fermentation, was used as a starter culture for traditional Spanish-style green olive fermentation. By means of a $2^{3}{ }_{(7-4)}$ fractional factorial design, the salt concentration in brines was found to be the most important factor for producing the highest acidity and the highest initial population of the starter culture. To a lesser extent, other factors such as a high inoculum size, use of MRS as carrier for the starter culture, inoculation time, and type of acid to correct the $\mathrm{pH}$ had also an overall significant effect on the final acidity or total corrected acidity. For all initial conditions investigated, $L$ b. plantarum LPCO10 was able to dominate over the natural population of lactic acid bacteria and leaded to a faster decrease of $\mathrm{pH}$ and a faster acidification than the spontaneous process during the first 25 days after brining. Then, wild lactobacilli grew slowly and the population of lactic cocci raised, while LPCO10 decreased. Inoculation also stimulated the growth of yeasts. Thus, the traditional fermentation of Spanish green table olives could be improved by using $L b$. plantarum LPCO10 (suspended in MRS) as a starter culture at $\geq 10^{7} \mathrm{cfu} / \mathrm{ml}$ of brine and well defined starting brine parameters i.e., $\leq 4 \% \mathrm{w} / \mathrm{v}$ of $\mathrm{NaCl}$, and initial $\mathrm{pH}$ correction (from 4.5 to 6.5 ) with acetic acid. Inoculation can take place in 1-4 days after brining.

Key words: Bacteriocin, olive fermentation, Lactobacillus plantarum, starter culture, yeast. 


\section{Introduction}

Production of Spanish-style green olives, like other natural vegetable fermentations, is a spontaneous, traditional lactic acid fermentation based on an empirical process which relies upon microorganisms present in the raw material and processing environment (Fernández Díez, 1983; Garrido Fernández et al. 1995). In the traditional process, olives are handled in order to favour the growth of Lactobacillus plantarum in the fermentation brines, which is thought to be essential to provide the amount of lactic acid needed for preservation as well as for its characteristic flavour. However, initial conditions are usually somewhat restrictive for the microbiological growth of desirable micro-organisms (Rodríguez de la Borbolla y Alcalá and Rejano Navarro, 1979; Rodríguez de la Borbolla y Alcalá and Rejano Navarro, 1981). The $L b$. plantarum population generally coexists with a yeast population until the end of the fermentation process and during storage (González Cancho, 1963; González Cancho and Durán Quintana, 1981; Rodríguez de la Borbolla y Alcalá et al. 1951; Ruiz-Barba, 1991; Ruiz-Barba et al. 1994; Vaughn, 1982). In some cases, lactic acid is not produced in the amounts needed for the adequate preservation of olives, and spoilage occurs through subsequent contamination by other micro-organisms (Fernández Díez, 1983; Garrido Fernández et al. 1995). In this regard, the use of suitable $L b$. plantarum starter cultures has the potential to improve the microbiological control of the process, increase the lactic acid yield and, accordingly, provide the production of Spanish-style fermented green olives of consistently high quality (Fernández Díez, 1983; Roig and Hernández, 1991; Ruiz-Barba, 1991; Garrido Fernández et al. 1995; Ruiz-Barba and Jiménez-Díaz, 1995). Recently, Sánchez et al. (2001) have investigated the use of starter cultures of lactobacilli at high pH.

Lactobacillus plantarum LPCO10, a strain originally isolated from a Spanish-style green olive fermentation, was shown to produce two bacteriocins, named plantaricins $\mathrm{S}$ and $\mathrm{T}$ (Jiménez-Díaz et al. 1993). These two bacteriocins were found to be active against a number of natural competitors of $L b$. plantarum in the fermentation brines and also against bacteria that can cause olive spoilage (Ruiz Barba, 1991). Lb. plantarum LPCO10 has been successfully used as a starter culture in olive fermentations (Ruiz-Barba et al. 1994) and it was assumed that the ability of LPCO10 to produce bacteriocins may facilitate its dominance over the natural microbial population. 
The aim of this work was to find the best initial conditions of brines to ensure the highest lactic acid formation and to study the physico-chemical and microbiological profile of table olive fermentation using $L b$. plantarum LPCO10 as a starter culture. As far as we know, this is the first time that a study of the simultaneous effect of several variables on a lactobacilli starter culture performance in green table olive fermentation is achieved.

\section{Materials and methods}

Brining procedure of olives. The traditional Spanish-style green olive brining procedure was followed (Garrido Fernández et al. 1995). Eight 500-litre pilot plant scale fermentors, containing $300 \mathrm{~kg}$ of whole Manzanillo green olives, Olea europaea Lineo, supplied by a local processor (Sevilla, Spain), were treated for $6 \mathrm{~h}$ with a $\mathrm{NaOH}$ solution $(2.1 \% \mathrm{NaOH}, \mathrm{w} / \mathrm{v})$ to reach $2 / 3$ of the flesh, washed in tap water for $15 \mathrm{~h}$, and then brined under the conditions derived from the experimental design showed in Tables 1 and 2. At the same time, other two fermentors were processed using the same lye and washing treatments as above but following the traditional spontaneous fermentation system, which consists of brining in an 11\% $\mathrm{NaCl}$ solution (Garrido et al. 1997). During the period of active fermentation, salt concentration was maintained at the levels fixed in the experimental design by periodical additions. Afterward, it was raised to $8.5 \%$ in all fermentors for the storage period. All fermentations were carried out at room temperature, which oscillated from $25{ }^{\circ} \mathrm{C}$, ten first days, to around $20^{\circ} \mathrm{C}$, the rest of the fermentation and storage period.

Bacterial strain. The strain $L b$. plantarum LPCO10, a bacteriocin producer previously isolated from a Spanish-style green olive fermentation (Jiménez-Díaz et al. 1993), was used as a starter culture. Spontaneous streptomycin-resistant isolates (LPCO10 $\mathrm{str}^{+}$) of the original strain were obtained as described previously (Ruiz-Barba et al. 1994).

Preparation of bacterial inocula for olive fermentation. Lactobacillus plantarum LPCO10 $\operatorname{str}^{\mathrm{r}}$ was subcultured twice at $30{ }^{\circ} \mathrm{C}$ in MRS broth (Oxoid, Unipath Ltd., Basingstoke, Hampshire, England) containing $500 \mu \mathrm{g} / \mathrm{ml}$ streptomycin (Sigma Aldrich, Madrid, Spain). Cultures in logarithmic phase of growth (O.D.600 of 1.5-2.0) were used as inocula. Before inoculation, aliquots of the cultures to obtain $10^{5}$ or $10^{7} \mathrm{cfu} / \mathrm{ml}$ after inoculation were 
centrifuged at $10000 \mathrm{~g}$, washed twice in saline $(0.85 \% \mathrm{w} / \mathrm{v} \mathrm{NaCl})$, and finally resuspended in $200 \mathrm{ml}$ sterile fresh MRS broth or saline.

Experimental design for olive inoculation and fermentation. The effect of different factors on the $L b$. plantarum LPCO10 strain behavior in the Spanish-style green olive fermentation was tested by a Placket-Burman $2^{3}$ (7-4) factorial design two levels (Box et al. 1978). The factors and their coded levels are shown in Table 1, and the complete experimental design is shown in Table 2. Periodically, brines were homogenized and samples were withdrawn from the center of the fermentors and analyzed as described below for their respective microbial (lactobacilli, lactic acid cocci, and yeasts) and physico-chemical characteristics ( $\mathrm{pH}, \mathrm{NaCl}$ concentration, combined, free and CTA). These results were the respective responses to the treatments.

Microbial growth in brines. Brine samples were diluted in saline, and the number of colony forming units per milliliter $(\mathrm{cfu} / \mathrm{ml})$ of the different microbial populations was determined by spreading the diluted samples on solid culture media with a Spiral System (Interscience, Saint-Nom-La-Bretèche, France). Yeast were enumerated aerobically at $25{ }^{\circ} \mathrm{C}$ on oxytetracycline-glucose-yeast extract agar (OGYE, Oxoid, Unipath Ltd., Basingstoke, Hampshire, England). Lactic acid bacteria (LAB) were enumerated aerobically on MRS agar (Oxoid, Unipath Ltd., Basingstoke, Hampshire, England) and MRS agar plus 0.02\% (w/v) sodium azide (Sigma Aldrich, Madrid, Spain) at $30{ }^{\circ} \mathrm{C}$. In order to distinguish lactic acid cocci from lactobacilli, colonies growing in those media were Gram stained and then microscopically examinated. In addition, Lb. plantarum LPCO10 was differentially enumerated at $30{ }^{\circ} \mathrm{C}$ on MRS agar containing streptomycin $(500 \mu \mathrm{g} / \mathrm{ml})$. All the plates for enumeration were incubated for $72 \mathrm{~h}$ and then the different microbial populations enumerated.

Analysis of olive brines. At the same sampling time as for the microbiological analysis, $\mathrm{pH}$, titratable and combined acidities, and $\mathrm{NaCl}$ concentration in samples of the fermentation brines from each fermentor were determined as described previously (Fernández Díez et al., 1985). Corrected total acidity, CTA, was calculated as the titratable acidity plus the combined acidity at equilibrium (expressed as percentage of lactic acid) minus the acidity used for initial pH correction (expressed also as percentage of lactic acid). 


\section{Statistical data analysis}

Data were statistically analyzed using the Design of Experiments and ANOVA/MANOVA modules of the Statistica package software (StatSoft Inc., 1996).

\section{Results and discussion}

\section{Physico-chemical profile}

Combined acidity ranged from 0.100 to 0.120 equivalents/liter $(\mathrm{N})$ and was similar for all fermentors.

$\mathrm{NaCl}$ concentrations oscillated around the levels fixed in the experimental design (4\% and $6 \%$ ) or the spontaneous process (6\%). They were maintained by periodical additions of solid salt. No spoilage or any other drawback was observed. The inoculation of $L b$. plantarum LPCO10 could have been decisive for this behavior. However, in the spontaneous traditional process the level of $4 \% \mathrm{NaCl}$ is considered insufficient and its use strongly disregarded (Garrido et al. 1997). Influence of this parameter level on the fermentation are commented below.

Changes in $\mathrm{pH}$, except for the initial values, were very similar for all treatments (Fig. 1). Values of $\mathrm{pH}$ decreased rapidly during the first ten days. Then the decrease slowed down but continued until the 30th day. After this moment, $\mathrm{pH}$ stabilized. The decrease of $\mathrm{pH}$ values in the spontaneous fermentation during the first 20 days was slower than in any other treatment but similar to that traditionally observed (Rodríguez de la Borbolla y Alcalá et al. 1958). Thus, inoculation with the LPCO10 starter culture leads to a faster $\mathrm{pH}$ decrease in green table olive processing with respect to the spontaneous one and this may help to reduce the risk of spoilage during the first days of fermentation (Garrido et al. 1997).

Changes in titratable acidity were scarce during the first five days and then raised rapidly (Fig. 2). Differences in the acidification process among treatments were observed since the beginning. Such differences were increasing during the first fifteen days and consistently established from that moment to the end of the fermentation. Treatment (or run) 8 always yielded the highest titratable acidity and, apparently, its conditions (Table 2) might be the most appropriate for a proper fermentation. Treatments (runs) 2, 3, and 4 gave also high titratable acidity with similar levels among them. The rest of the treatments as well as the spontaneous process yielded the lowest values. Therefore, regarding to the initial brining conditions, inoculation not necessarily leads to the production of higher values of acidity. Thus selection of appropriate initial brining conditions is important to increase the titratable 
acidity by inoculation. The experimental design may help to the assessment of the effects of the different variables and establish the best initial brining conditions.

\section{Selection of the best initial brining conditions based on acidity production.}

The effects (average effect of each variable over all conditions of the others) of the initial brining variables on the production of titratable acidity were calculated for each sampling data following Box et al. (1978), and their values represented throughout the fermentation period (Fig. 3a). Positive values of effects mean that the levels of variables coded as +1 are favorable. Negative values indicate that levels coded as -1 are better. Significance was estimated using pooled SE. Effects showed oscillations at the beginning of the fermentation (5-15 days) and, as fermentation progressed, they showed a consistent pattern, with a general tendency to decrease their magnitudes as the process progressed. This behavior demonstrates the essential role played by the initial conditions on the subsequent acidification.

Salt concentration had the strongest effect (significant at $\mathrm{p}<0.05$ ). This effect was negative, as the low level of $\mathrm{NaCl}(4 \%, \mathrm{w} / \mathrm{v})$ produced the highest titratable acidity. This influence of the initial salt content was also observed by Rodríguez de la Borbolla y Alcalá et al. (1951) and Durán Quintana et al. (1999), who found that low initial salt concentration is a critical factor for a proper lactic acid fermentation of olives at low temperature, and by Ballesteros et al. (1999) for other traditional fermented vegetables.

The effect of initial $\mathrm{pH}$, inoculation time, and inoculum carrier (except for the last sampling date) were also outstanding. High inoculum size had also positive effects. Use of acetic acid for the $\mathrm{pH}$ correction was also favorable on the long term.

However, the study of the effects based on only the titratable acidity might be masked by the acid added to some fermentors for the initial correction of brine $\mathrm{pH}$. To prevent this possible error, the same analysis of effects have also been repeated using the CTA (Fig 3b). Absolute values of effects are higher than those estimated from titratable acidity, but the results of the analysis changed only slightly.

The effect of salt on CTA was also the most outstanding and significant $(\mathrm{p}<0.05)$. The size of the inoculum showed the next significant strongest effect $(\mathrm{p}<0.05)$ in absolute terms. Its position is now consistent throughout the fermentation period and clearer than when effects were calculated from titratable acidity. Inoculation of $10^{7} \mathrm{cfu} / \mathrm{ml}$ yielded the highest CTA. 
The effects of the inoculum carrier was also noticeable $(p<0.05)$. The use of MRS as a carrier for the cells of $L b$. plantarum improved acidification with an apparent maximum at the 10th day of fermentation. Then decreased progressively but still maintaining remarkable values. As final concentration of the components of MRS in the fermentors is very low, for it was diluted 2500 times, only growth factors required in very small amounts by $L b$. plantarum cells (vitamins, amino acids, or trace elements) could play a role (Ruiz-Barba and Jimenez Díaz, 1994 and 1995). The positive effect of MRS could also be explained by its protective effect on $L b$. plantarum cells. A similar positive effect of MRS on $L b$. plantarum growth had been also observed in the presence of other stressing conditions (Ruiz-Barba, 1991; Durán Quintana et al. 1994).

The effect of the inoculation time increased within the first 15 days and remained constant, and similar to that of the inoculum carrier, for the rest of the fermentation. The most favorable CTA value was achieved when the inoculation took place at the 4th day after brining.

The effect on CTA of the acid used to lower the initial $\mathrm{pH}$ was the third one in absolute value at the end of the fermentation and showed significant effect at this moment $(p<0.05)$. This behavior is similar to that observed on titratable acidity. The effect of the initial $\mathrm{pH}$ showed a negative value around the 10th day, but it became less important as the fermentation progressed, being close to zero at the end of the process (Fig. 3b). Thus, its overall effect on CTA was not significant. Apparently, the greatest difference between using titratable acidity or CTA in the statistical analysis is observed on initial $\mathrm{pH}$. Such difference may disclose the influence of the amount of acid added to $\mathrm{pH}$ correction (hidden variable) and help to obtain valid conclusions. Finally, for the size of the fermentors used in this experiment, homogenization of brine after inoculation had always a very low effect, which was practically zero at the end of the fermentation period (Fig. 3).

The effect of salt on titratable acidity is depicted in Fig. 4. Average values of titratable acidity obtained in treatments with $4 \% \mathrm{NaCl}$ were always above those of $6 \%$, which, in turn was similar to that of the spontaneous process. Thus, when using a $6 \% \mathrm{NaCl}$, inoculation had not any effect on the final titratable acidity with respect to the spontaneous process. This justifies the prevention of the industry in relation to the use of starters, which usually are added without any other modification in the brining conditions. However, inoculation, irrespective of the initial $\mathrm{NaCl}$ concentration and inoculum size produced a faster acidification than that obtained in the spontaneous process. Thus, inoculation is strongly advisable to 
accelerate acidification during the first stage of the fermentation and reduce the risks of spoilage.

From the physico-chemical point of view, the most appropriate combination of initial conditions for olive brining when inoculation with $L b$. plantarum LPCO10 and, most probably, other starters is intended are: $4 \% \mathrm{NaCl}$, high inoculum size, inoculation at the 4th day, use of MRS as suspending medium, and utilization of acetic acid for acidification. In terms of CTA, the use of these initial brining conditions can produce an overall increase of about $0,6 \%$, mainly due to low salt (about $0.30 \%$ ), high inoculum $(0.15 \%)$, and the use of MRS as starter carrier (0,10\%). Expressed as titratable acidity, improvement may be estimated as $0,3 \%$ with a similar distribution. At the industrial scale, it could be advisable, at least, to decrease the initial $\mathrm{NaCl}$ concentration up to $4 \%$, a slight initial $\mathrm{pH}$ correction with acetic acid, and a heavy inoculation with $L$ b. plantarum LPCO10.

\section{Microbiological profile.}

Changes in the populations of the inoculated $L b$. plantarum LPCO10 strain and indigenous lactobacilli followed a similar pattern in all treatments. Figure 5 shows the average values for total lactobacilli population and that of LPCO10. The inoculated LPCO10 strain rapidly proliferated in the brines, delaying the growth of the indigenous lactobacilli. This delay was maximal for fermentation 3 (data not shown), in which spontaneous lactobacilli appeared only after 30 days of fermentation, but the average delay was about 20 days. Then, the LPCO10 strain decreased slowly and the indigenous lactobacilli population increased. However, the population of the inoculated $L b$. plantarum LPCO10 strain was always an important proportion of the total population and persisted up to the end of the process.

This behavior must be emphasized since in the spontaneous fermentation an ecological succession of the indigenous strains is usual (Ruiz-Barba et al. 1994; Ruiz-Barba and Jiménez-Díaz 1994), and agrees with previous results using Lb. plantarum LPCO10 as a starter culture (Leal et al. 1998; Ruiz-Barba et al. 1994). As it was proposed in these studies, the ability of the inoculated LPCO10 strain to produce plantaricin S and T in olive brines was assumed to contribute to the predominance of the producer strain over the indigenous microflora (Ruíz-Barba et al. 1994). In the present case, the favourable initial conditions for the growth of $L b$. plantarum LPCO10 in the olive brines might also positively influence the amount of plantaricin $\mathrm{S}$ and $\mathrm{T}$ produced by this strain, thus contributing to a more effective control of the indigenous lactobacilli and other lactic acid bacteria. However, the total number of the lactobacilli in the inoculated fermentors was similar to that in the spontaneous process 
(Fig. 5) and similar to those found in previous studies (Fernández Díez et al. 1985; RuizBarba et al. 1994). In other studies (Rodríguez de la Borbolla y Alcalá et al. 1964; Ruiz-Barba et al. 1994), a decrease in the cell count of the starter culture just after inoculation has been observed. Pelagatti and Brighigna (1981) assayed various procedures to reduce such effect. However, no significant decrease in the inoculum cell count was observed in the present study (Fig. 5). This might have been due to the favorable initial conditions used here.

No differences on yeast growth between treatments were observed in the case of inoculation with LPCO10 strain, even in the case of different inoculum sizes (Fig. 6). However, the yeast population found in the inoculated processes after the 20th first days of brining was significantly higher than that observed in the spontaneous fermentation. This result was unexpected and needs further research to be clarified.

The growth of lactic acid cocci (Fig. 6) was observed before the inoculation with $L$ plantarum LPCO10 that took place at the 4th day of the brining. However, after the addition of the inoculum they were inhibited for a period. Subsequently, as the LPCO10 lactobacilli population decreased, the growth of cocci raised rapidly. Thus, at the end of the fermentation, the population of lactic acid cocci was always higher than that of lactobacilli. Similar results were also reported by Durán Quintana et al. (1994)

Apparently, the microbiological control caused by the inoculation with $L b$. plantarum LPCO10 was completely effective during about the first 20 days. Then the wild microflora increases, although inoculation had also a marked effect on the changes in the population of the different microorganisms throughout the rest of the fermentation.

\section{Selection of the best initial brining conditions based on microbial growth.}

Effects of initial brining conditions on $L b$. plantarum LPCO10 throughout the fermentation period were not consistent but cyclical (Fig. 7). Apparently, a period of favorable effect is usually followed by other that is unfavorable. Apparently, the population increase at the beginning leads to a major production of metabolites, including lactic acid, which, in turn, might lead to a decrease in the population for the following period. The opposite occurs in the next cycle. The first cycle lasted about 20 days and was defined by the period in which the LPCO10 exerts a complete control on the lactic acid bacteria in brine. The end of this cycle coincided with the initiation of the growth of wild lactobacilli and cocci and a loss in the efficiency of the fermentation control by the LPCO10 strain.

There was a significant effect of salt at the beginning of the process that was maintained for about the first 20 days. Then the absolute values of effects decreased with time 
following the cyclical pattern above commented. The effect of inoculum size was significant only in the first sampling date and practically disappeared throughout the rest of the fermentation period. The same behavior was followed by the initial correction of $\mathrm{pH}$ at 4.0. The use of a proper carrier for the inoculum improved the population during the first 20 days. Then, as usual, inverted the tendency for one cycle and approached to zero slowly. The LPCO10 population was also higher during the first cycle when inoculated at the first day. The other variables had limited effects, although also followed the same cycling behavior.

The effects of initial brining conditions on yeasts followed the same pattern that the above described for LPCO10, with the exception of the first part at the very beginning of the process. In most of the cases, the effects were of different sign than those found on LPCO10, indicating an opposite response of their respective populations to the same variables. The two most outstanding $(\mathrm{p}<0.05)$ effects, due to salt concentration and inoculum size, were found at the 10th day. The low coded value of the other variables were favorable for yeast growth for the first 20 days. Then the absolute values of the effects decreased for all variables and followed the above mentioned cycling evolution.

From the analysis of the effects on microbial population, especially LPCO10, it can be deduced that the best initial conditions to facilitate the inoculum survival are $4 \% \mathrm{NaCl}$, as high as possible inoculum size, initial $\mathrm{pH}$ correction to 4.0, and use of MRS as carrier. These conditions coincide with those deduced from the effects on titratable or corrected total acidity. However, inoculation at 1 day after brining leaded to higher LPCO10 population while the $4^{\text {th }}$ day was more favorable for acidity or CTA.

In general, a good green table olive fermentation is characterized by a rapid production of high acidity, low $\mathrm{pH}$, and high population of lactobacilli. Results obtained in this work have demonstrated that the initial brining conditions can affect the titratable or total corrected acidity produced and the inoculum growth. The best initial brine conditions for inoculation with the bacteriocin producer LPCO10 strain, deduced from the physico-chemical and microbiological results, are $4 \% \mathrm{NaCl}$, inoculum size of $10^{7} \mathrm{cfu} / \mathrm{ml}$ (or above), addition into the fermentors of the MRS used for suspending the starter culture, inoculation after 4 days of brining (or 1 day if only considered the LPCO10 population), and an initial moderate correction of $\mathrm{pH}$ with acetic acid to 4.0. Trials to confirm these results at industrial scale are underway, although we expect a similar behavior due to the same shape of the fermentors used in these experiments and their relatively large volume. 
Inoculation, when appropriate initial conditions are selected, accelerates the $\mathrm{pH}$ decrease during the first phase of the fermentation and yields higher free and corrected total acidities than the spontaneous process. Inoculation also alters the usual microbiological evolution of the spontaneous process since the inoculated strain initially inhibits the wild lactobacilli and remains as a marked proportion of the total population of these microorganisms until the end of the fermentation. Yeast population in inoculated fermentors was higher than in the spontaneous process, specially in the last fermentation phases. The consequences of this change are still unknown. Inoculation with LPCO10 inhibited the lactic acid cocci population, but they always survived after a certain period and overcame the lactobacilli population.

\section{ACKNOWLEDGMENTS}

This work was supported in part by contracts from the Spanish Government (CICYT projects ALI97-0658-C03-01, ALI97-0646, and AGL2000-1539-CO2-01) and the EU (FAIR97-9526).

We are grateful to M.J. Revillas Martínez, F. Rodríguez and E. Cabello Ferrera for skilful technical assistance.

\section{References}

Ballesteros, C., Palop, L., Sánchez, I. (1999) Influence of sodium chloride on the controlled lactic acid fermentation of “Almagro” eggplants. Int. J. Food Microbiol. 53, 13-20.

Box, E.P.G., Hunter, G.W., Hunter, J.S. (1978) In: Statistics for experimenters. An introduction to design, data analysis and model building. pp. 374-418. New York. John Willey \& Sons.

Durán Quintana, M.C., García, P., Brenes, M., Garrido, A. (1994) Induced lactic fermentation during the preservation stage of ripe olives from Aloreña cultivar. J. Appl. Bacteriol. 76, 377382. 
Durán Quintana, M.C., García García, P., Garrido Fernández, A. (1999) Establishment of conditions for green table olive fermentation at low temperature. Int. J. Food Microbiol. 51, 133-143.

Fernández Díez, M.J. 1983. Olives, In Biotechnology: Food and Feed Production with Microorganisms(Eds H.-J. Rehm and G. Reed ). pp. 379-397. Florida. Verlag.

Fernández Díez, M.J., de Castro Ramos, R., Garrido Fernández, A., González Cancho, F., González Pellissó, F., Nosti Vega, M., Heredia Moreno, A., Mínguez Mosquera, M.I., Rejano Navarro, L., Durán Quintana, M.C., Sánchez Roldán, F., García García, P., de Castro, A. (1985) In Biotecnología de las Aceitunas de Mesa. pp. 51-123. Madrid. CSIC.

Garrido Fernández, A., Fernández Díez, M.J., Adams, R.M. (1997) In Table Olives. Production and processing. pp.134-197. London. Chapman \& Hall.

Garrido Fernández, A., García García, P., Brenes Balbuena, M. (1995) Olive fermentations, In Biotechnology: Enzymes, Biomass, Food and Feed (Eds H.-J. Rehm and G. Reed). pp. 593-627. New York. VCH.

González Cancho, F. (1963) Microorganismos que se desarrollan en el aderezo de aceitunas verdes estilo español. Microbiología Española, 16, 221-230.

González Cancho, F., Durán Quintana, M.C.. (1981) Bacterias cocáceas del ácido láctico en el aderezo de aceitunas verdes. Grasas y Aceites 32, 373-379.

Jiménez-Díaz, R., Rios-Sánchez, R.M., Desmazeaud, M., Ruiz-Barba, J.L., Piard, J.-C. (1993) Plantaricins S and T, two new bacteriocins produced by Lactobacillus plantarum LPCO10 isolated from a green olive fermentation. Appl. Environ. Microbiol. 59, 1416-1424.

Leal, M.V., Baras, M., Ruiz-Barba, J.L., Floriano, B., Jiménez-Díaz, R. 1998. Bacteriocin production and competitiveness of Lactobacillus plantarum LPCO10 in olive juice broth, a culture medium obtained from olives. Int. J. Food Microbiol. 43, 129-1134. 
Pelagatti, O., Brighigna, A. (1981) The reviving and use of dried lactic acid bacteria for table olives preparation by “Sivigliano system”. Industrie Alimentarie, March,182-184.

Rodríguez de la Borbolla y Alcalá, J.M., Gómez Herrera, C., Gutiérrez González-Quijano, F., Vázquez Ladrón, R. (1951) La concentración de la salmuera. Estudios sobre el aderezo de aceitunas verdes. Sevilla. Asociación de Exportadores de Aceitunas de Mesa.

Rodríguez de la Borbolla y Alcalá, J.M., Rejano Navarro, L. (1979) Sobre la preparación de las aceitunas estilo sevillano. La fermentación I. Grasas y Aceites 30, 175-185.

Rodríguez de la Borbolla y Alcalá, J.M., Rejano Navarro, L. (1981) Sobre la preparación de las aceitunas estilo sevillano. La fermentación II. Grasas y Aceites 32, 103-113.

Rodríguez de la Borbolla y Alcalá, J.M., Gómez Herrera, C., González Cancho, F., Fernández Díez, M.J. (1958) Estudio sobre el aderezo de aceitunas verdes. XV. La primera fase de la fermentación. Grasas y Aceites 9, 118-124.

Rodríguez de la Borbolla y Alcalá, J.M., Fernández Díez, M.J., González Cancho, F. (1964) Empleo de cultivos puros de lactobacilos en la preparación de aceitunas verdes. Grasas y Aceites 15, 6-11.

Roig, J.M., Hernández, J.M. (1991) El uso de microorganismos iniciadores (starters) en la fermentación de aceitunas. Olivae 37, 20-28.

Ruiz-Barba, J.L. (1991) Ph. D. Thesis. University of Seville, Seville, Spain.

Ruiz-Barba, J.L., Cathcart, D.P., Warner, P.J., Jímenez-Díaz, R. (1994). Use of Lactobacillus plantarum LPCO10, a bacteriocin producer, as a starter culture of Spanish-style green olive fermentations. Appl. Environ. Microbiol. 60, 2059-2064.

Ruiz-Barba, J.L., Jiménez-Díaz, R. (1994) Vitamin and amino acid requirements of Lactobacillus plantarum isolated from green olive fermentations. J. Appl. Bacteriol. 76, 350355. 
Ruiz-Barba, J.L., Jiménez-Díaz, R. (1995) Availability of essential B-group vitamins to Lactobacillus plantarum in green olive fermentation brines. Appl. Environ. Microbiol. 61, 1294-1297.

Sánchez, A.H., Rejano, L., Montaño, A. Castro, A. de (2001) Utilization at high pH of starter cultures of lactobacilli for Spanish-style green olive fermentation. Int. J. Food Microbiol. 67, 115-122.

StatSoft Inc. (1996) Statistica for windows (Computer Program Manual), Tulsa, OK.

Vaughn, R.H. (1982) The fermentation of olives. In Industrial Microbiology, $4^{\text {th }}$ edition (Eds G. Reed). pp. 206-236. Westport. AVI. 
Table 1.- Factors and coded levels of the $2^{3}{ }_{(7-4)}$ fractional factorial design (Box et al, 1978) used as a screening design for $L b$. plantarum LPCO10 strain inoculation in olive fermentations.

\begin{tabular}{|c|c|c|}
\hline \multirow[t]{2}{*}{ Factor } & \multicolumn{2}{|c|}{ Coded level } \\
\hline & -1 & +1 \\
\hline Inoculum size $(\mathrm{cfu} / \mathrm{ml})^{\mathrm{a}}$ & $10^{5}$ & $10^{7}$ \\
\hline Homogenization $^{\mathrm{b}}$ & no & yes \\
\hline Inoculum carrier & saline & MRS \\
\hline Acid type ${ }^{c}$ & acetic acid & $\mathrm{HCl}$ \\
\hline Time of inoculation $^{\mathrm{d}}$ & 1 day & 4 days \\
\hline Initial $\mathrm{pH}$ & 4.5 & 6.5 \\
\hline $\mathrm{NaCl}$ concentration (w/v) & $4.0 \%$ & $6.5 \%$ \\
\hline
\end{tabular}

${ }^{\mathrm{a}}$ Final concentration in the fermentors. ${ }^{\mathrm{b}}$ When applied, homogenization took place immediately after inoculation, by re-circulating the brine from the bottom to the top with a pump for approximately 15 minutes. ${ }^{c}$ Acid used to decrease the basic, initial $\mathrm{pH}$ of the brines. ${ }^{\mathrm{d}}$ Number of days after brining when inoculation took place. 
Table 2. Placket-Burman ( $2^{3}{ }_{(7-4)}$ fractional factorial) design (Box et al., 1978) used for fixing the initial condition of brines in the different Lb. plantarum LPCO10 strain inoculations.

\begin{tabular}{cccccccc}
\hline $\begin{array}{l}\text { Run } \\
\text { number }\end{array}$ & $\begin{array}{c}\text { Inoculum } \\
\text { size }\end{array}$ & Homogenization & $\begin{array}{c}\text { Type of } \\
\text { inoculum }\end{array}$ & $\begin{array}{c}\text { Type of } \\
\text { acid }\end{array}$ & $\begin{array}{c}\text { Inoculation } \\
\text { date }\end{array}$ & $\begin{array}{c}\text { Initial } \\
\mathrm{pH}\end{array}$ & $\begin{array}{c}\text { Salt } \\
\text { concentration }\end{array}$ \\
\hline 1 & +1 & +1 & +1 & -1 & +1 & +1 & +1 \\
2 & -1 & +1 & -1 & +1 & -1 & +1 & -1 \\
3 & +1 & -1 & -1 & +1 & +1 & +1 & -1 \\
4 & -1 & -1 & +1 & -1 & -1 & +1 & -1 \\
5 & +1 & -1 & -1 & -1 & -1 & -1 & +1 \\
6 & -1 & -1 & +1 & +1 & +1 & -1 & +1 \\
7 & +1 & +1 & +1 & +1 & -1 & -1 & +1 \\
\hline
\end{tabular}




\section{Legends to Figures}

Figure 1.- Changes in the $\mathrm{pH}$ of the fermentors brine during the period of active fermentation. See Tables 1 and 2 for the initial brining conditions.

Figure 2.- Changes in titratable acidity of the fermentors brine during the period of active fermentation. Pooled standard deviation, 0.03 (8 df). See Tables 1 and 2 for the initial brining conditions.

Figure 3.- Estimated effects of the different parameters studied on titratable acidity and corrected total acidity (CTA) throughout the period of active fermentation (Pooled SE with 8 df, 0,02 and 0.03, respectively).

Figure 4.- Effect of salt concentration on the changes in titratable acidity of the inoculated fermentations (Pooled SD, 0.02 with $8 \mathrm{df}$ ) versus the spontaneous process during the period of active fermentation.

Figure 5. - Average growth (Pooled SD, 0.10 with $16 \mathrm{df}$ ) curves of the inoculated $L b$. plantarum LPCO10 strain, and indigenous, natural lactobacilli populations in the experimental inoculated fermentors versus the total lactobacilli population in the spontaneous one.

Figure 6.- Effect of the $L b$. plantarum LPCO10 inoculation versus the spontaneous process on the yeast growth (Pooled SD, 0.13 with $14 \mathrm{df}$ ) as well as the average growth of lactic cocci population for all inoculated fermentors (Pooled SD, 0.16 with $8 \mathrm{df}$ ).

Figure 7.- Estimated effects of the different parameters studied on the LPCO10 population (a) and yeasts (b) throughout the period of active fermentation (Pooled SE, 0,14 and 0.25, respectively, with $8 \mathrm{df}$ ). 


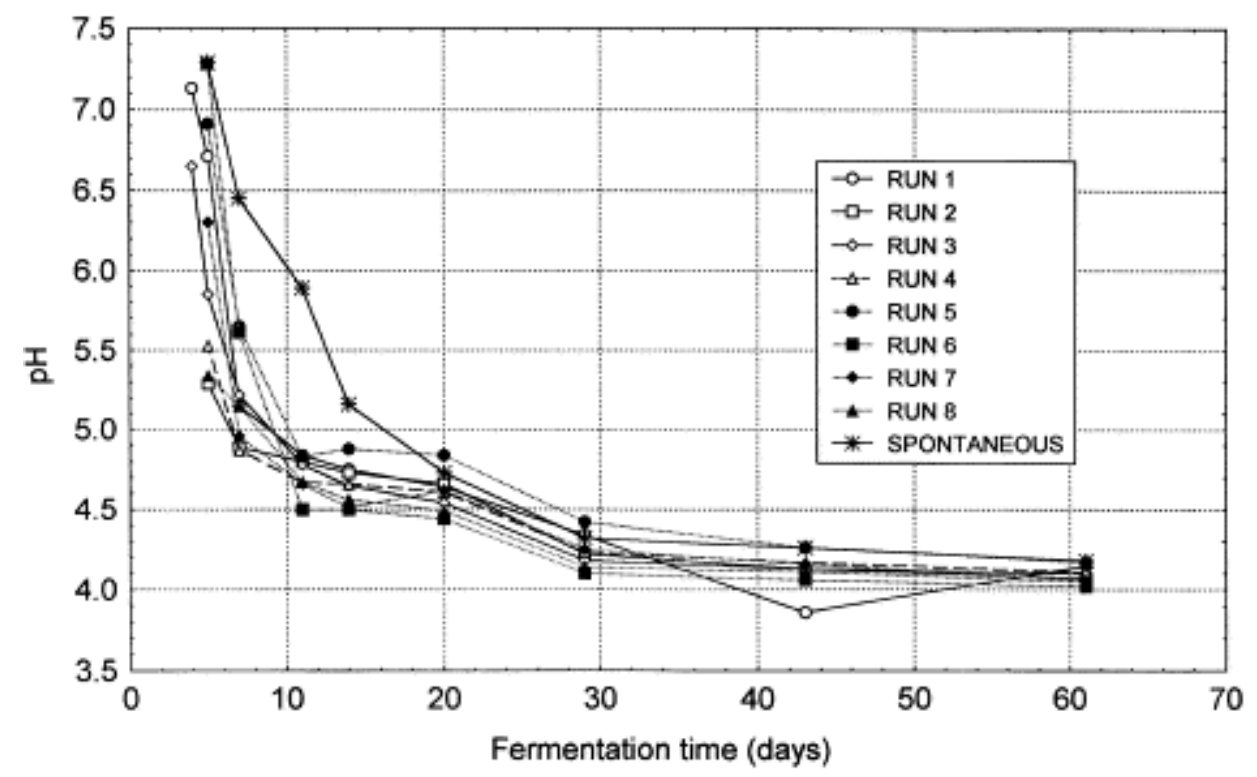

Figure 1

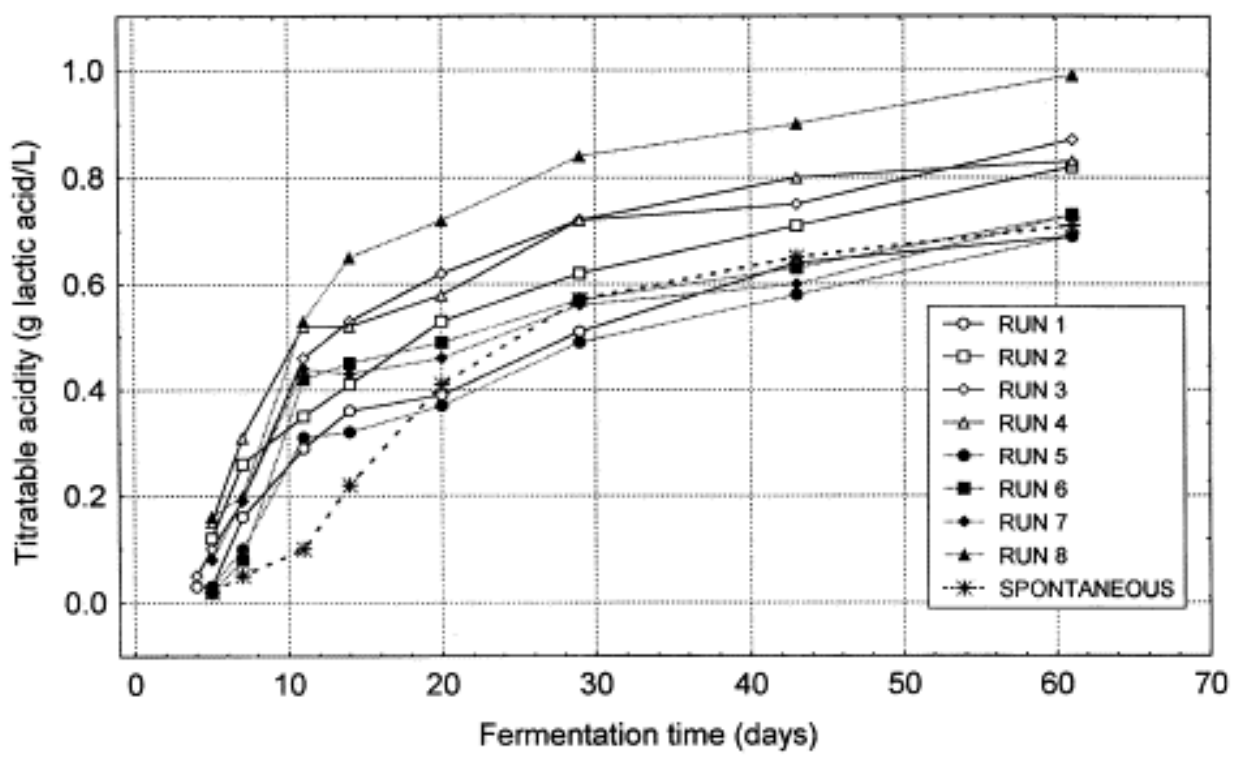

Figure 2 

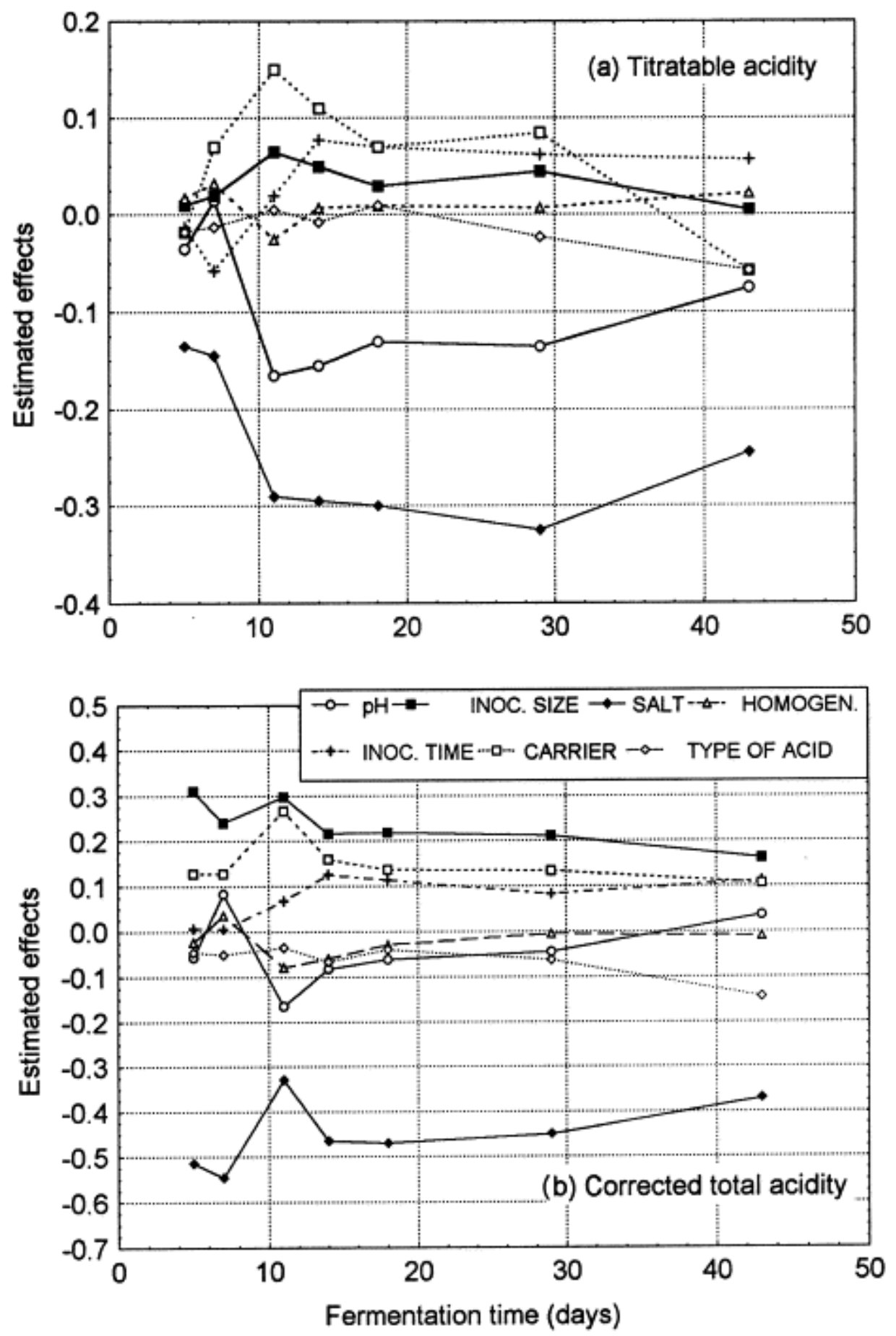

Figure 3 


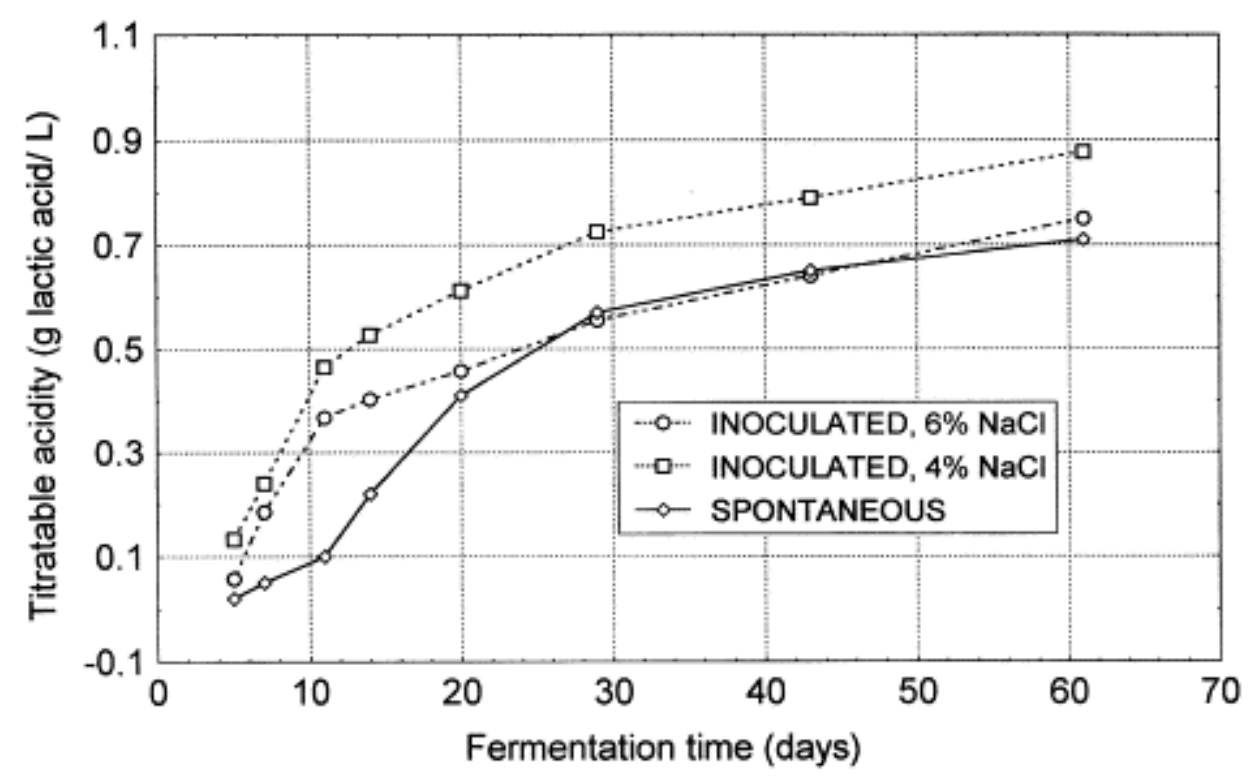

Figure 4

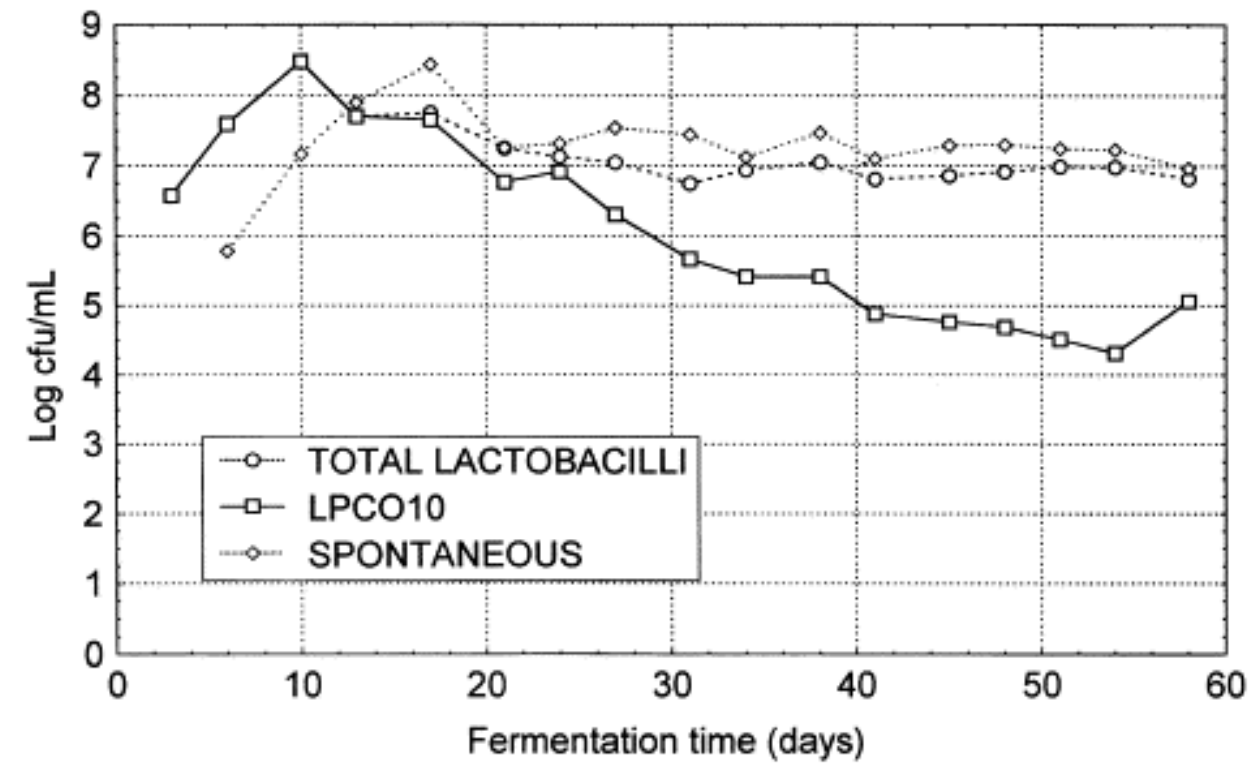

Figure 5 


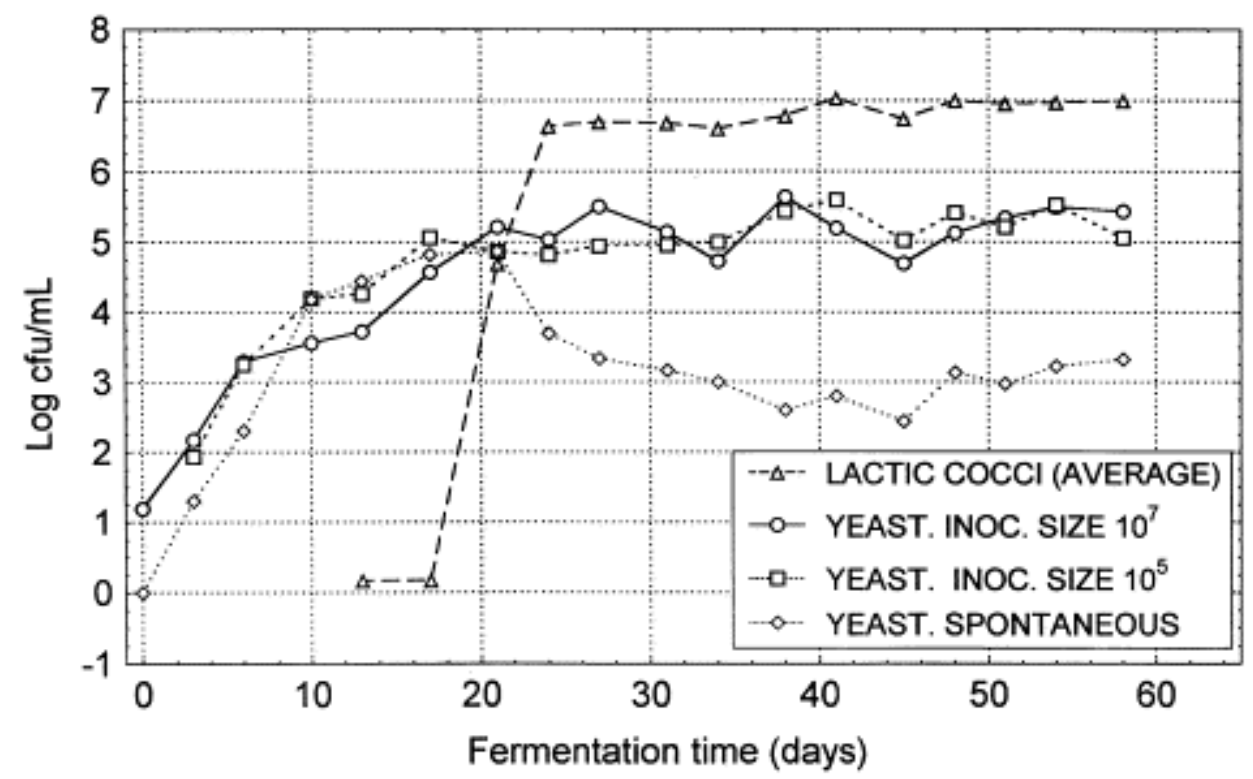

Figure 6 

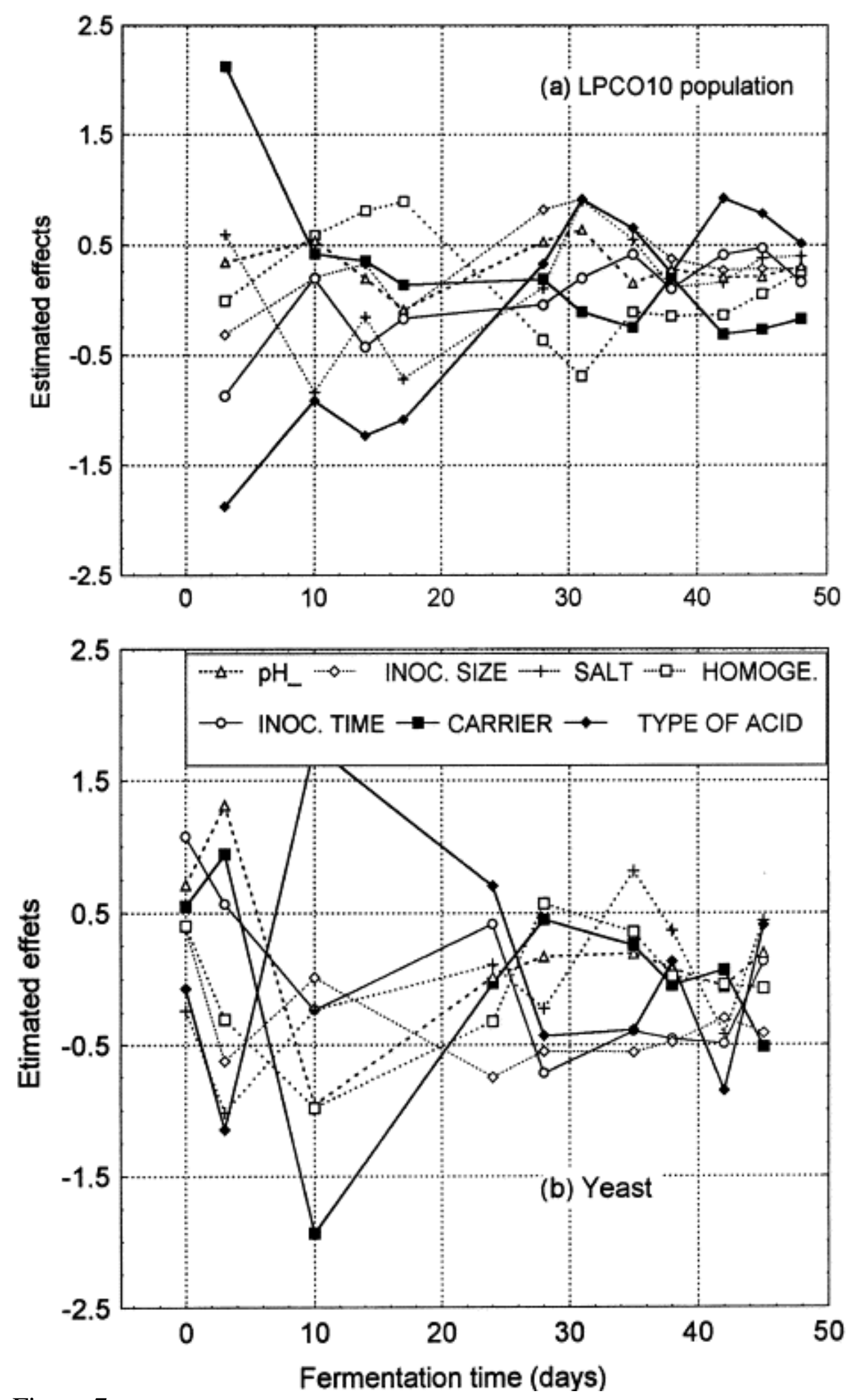

Figure 7 